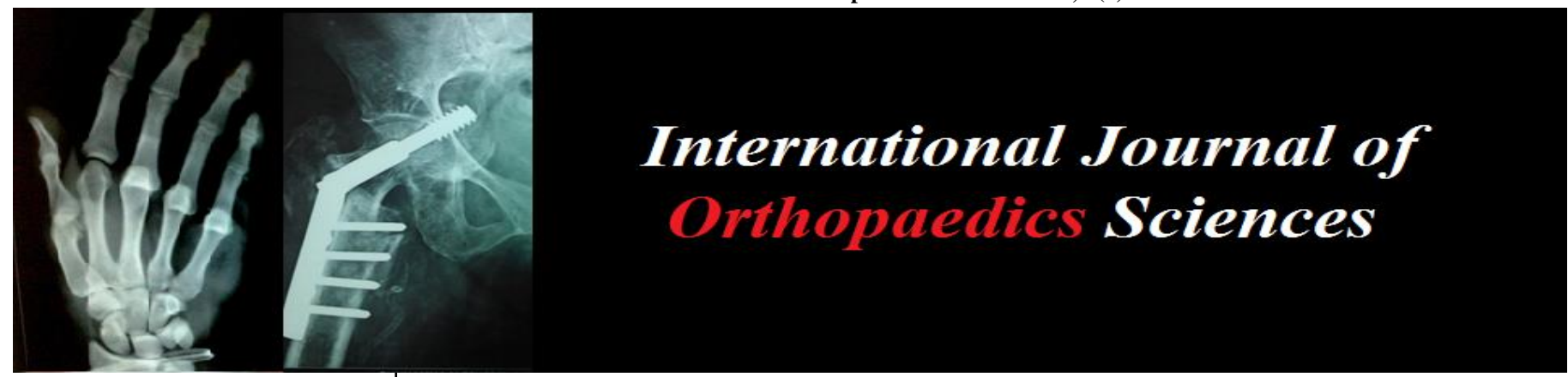

E-ISSN: 2395-1958

P-ISSN: 2706-6630

IJOS 2019; 5(4): 01-04

(C) 2019 IJOS

www.orthopaper.com

Received: 01-08-2019

Accepted: 04-09-2019

Dr. Nilesh Indulal Kachnerkar Associate Professor, Department of Orthopaedics, Government Medical College Jalgaon,

Maharashtra, India

Dr. Lakhwinder Singh Associate Professor, Department of Orthopaedics, Dr. Ulhas Patil Medical College Jalgaon,

Maharashtra, India
Corresponding Author: Dr. Lakhwinder Singh Associate Professor, Department of Orthopaedics, Dr. Ulhas Patil Medical College Jalgaon,

Maharashtra, India

\section{Comparision between nailing and compression plating in the treatment of fracture shaft radius and ulna}

\author{
Dr. Nilesh Indulal Kachnerkar and Dr. Lakhwinder Singh
}

DOI: https://doi.org/10.22271/ortho.2019.v5.i4a.1636

Abstract

Forearm fractures i.e. fractures of shaft of radius and ulna are very common in todays high speed life. There are variable treatment options available including plaster cast, nailing and plating which are most common modalities of treatment. Considering the advantages and disadvantages of all the available modalities of treatment, the present study is an attempt to asses and compare the results of nailing and plating in fractures of shaft of radius and ulna over a period of three years. Multiple aspects of results and outcome have been studied and compiled so that it will be helpful for other orthopaedic surgeons and students in making a decision in management of forearm fractures. The study included a total of 25 patients.

Keywords: Comparative study, radius ulna fractures, nailing, plating

\section{Introduction}

The radius and ulna bones belong to the upper extremity and that makes proper treatment of their fractures very important as day to day function of an individual depends on it. Restoration of full function of forearm fractures is of paramount importance as it directly affects individuals physical, mental, economical and social status thus making them challenging for ortho paedicians to treat. Radius ulna fractures present specific problems encountered only in this area of body. Treatment of fractures of forearm bones does not mean only healing but aims at achieving good function along with bone union. This can be done by proper anatomical reduction of broken bones with preservation of vascularity and soft tissue continuity aided by stable mechanical fixation. Angulations and rotational stress are the challenges encountered which are difficult to eliminate and can displace the reduction of fracture which was achieved. These complex forces acting on the bones makes conservative means of treatment unstable and obsolete specially in adults. In addition, the proximal and distal radio-ulnar joint will not function properly if above parameters are not corrected. Successful treatment is one with perfect union, good muscle strength, restoration of joint movements and pain relief. Considering all these pros and cons, the present series studies the comparative results of nailing and plating in forearm bone fractures.

\section{Material and Methods}

The study was conducted over 3 years. The study included a total of 25 patients. It included both simple and complicated fractures. All fractures were managed by open reduction and internal fixation either with a nail or plate. In this series fixation was carried out after doing appropriate preoperative clinical, radiological and lab investigations. All the fractures were acute post-traumatic with no pathological fractures.

Inclusion Criteria: All patients within the age group of 18 to 60 years.

Exclusion Criteria: Children, Pathological fractures, Monteggia and Galleazi \#.

Procedure Done

Both bone nailing: 11 patients

Both bone plating: 10 patients 


$\begin{array}{ll}\text { Hybrid fixation: } & 04 \text { patients } \\ \text { Total: } & 25 \text { patients }\end{array}$

Preoperative management: All patients were initially given primary treatment by long arm posterior slab. Wound wash was given for compound patients and all other primary treatment given. Pre-anesthetic evaluation was done and patient kept NBM for 8 hours. The poper surgical site preparation was done. Informed, valid written consent was taken from patient as well as relatives.

Implant selection: Fractures were either fixed with square nails for both bones or $3.5 \mathrm{~mm}$ DCP for both bones or hybrid fixation was done i.e. $3.5 \mathrm{~mm}$ DCP for Radius and square nail for Ulna. In case of a nail, length of the bone was clinically measured on uninjuried limb. Diameter of nail was determined from X-ray and confirmed at the time of surgery on table.

Anesthesia: either general or regional block anesthesia was administered.

Surgical operative technique: The patient was positioned supine on the operative table with the forearm over an arm board. Pre-operative antibiotic was given half hour before procedure. Limb was exanguiated and a pneumatic tourniquet was applied. Painting and draping was done with scrub and solution respectively. Then tourniquet was inflated for average time period if 60 minutes.

Radius: Either a dorsal Thompson or volar Henry approach was used depending upon the level of the fracture site. After cutting through the skin and subcutaneous tissue, soft tissue planes were created and fracture site exposed. Fracture edges were freshend and traction counter traction given and manipulation done and reduction was achieved.

Nailing: Radial styloid was exposed through the anatomical snuff box and a entry point made with awl, cannal rimmed and appropriate size nail was hammered maintaining reduction.

Plating: After achieving reduction, a $3.5 \mathrm{~mm}$ DCP was applied over fracture site such that at least 6 cortices were available for each fragment. Appropriate size screws were inserted.

Ulna: Fracture was exposed by taking incision over subcutaneous border of ulna. Subcutaneous tissue planes created and fracture site exposed.

Nailing: Retrograde nailing technique was used for ulna nailing after opening fracture site.

Plating: After achieving reduction with bone holding forceps $3.5 \mathrm{~mm}$ DCP was used to satbilize fracture and appropriate size screws used. Periosteal stripping was kept to minimum both in nailing as well as plating so that it does not interefere in bone healing. Wound closure was done in layers over a drain after giving appropriate wash.

Post-operative management: At the end of the procedure, above elbow posterior slab was applied, strict hand elevation given. Intravenous antibiotics was given for 5 days, then shifted to oral antibiotics for next 5 days. Check dressing was done on day 5 and suture removal was done on day 12. Range of motion movements were started on day 14. Radiological evaluation was done at 4 weeks, 8 weeks and 12 weeks. Light work allowed at 6 weeks and normal working started after union.

\section{Results}

Results of radius ulna fracture surgery depends on multiple of factors. Result here is based on criteria laid down by Fredrick Marek for union.

\section{Excellent}

Radiological-Perfect alignment without rotational deformity Functional - No restriction of pronation-supination, No restriction of elbow and wrist flexion/extension

\section{Good}

Radiological- Minimal step formation, angulation <15 degree, no rotational deformity.

Functional - Restriction of pronation-supination $<15$ degree Restriction of elbow and wrist flexion/extension $<15$ degree.

Poor

Radiological- Angulation >15 degree, rotation deformity, mal union, non-union.

Functional - Restriction of pronation-supination $>15$ degree Restriction of elbow and wrist flexion/extension $>15$ degree. Depending upon the above criteria

Table 1: We have the following results of the current study

\begin{tabular}{|c|c|c|}
\hline Grading of Results & No. of cases & Percentage \\
\hline Excellent & 14 & 56 \\
\hline Good & 08 & 32 \\
\hline Poor & 03 & 12 \\
\hline Total & 25 & 100 \\
\hline
\end{tabular}

Excellent results are more common in the plated group. Poor results are either due to delayed union ( 2 cases) or non-union (1 case).

Complications: In the present series, the following complications are observed:

Table 2: Type of complications

\begin{tabular}{|c|c|}
\hline Complications & No. of Cases \\
\hline PIN Palsy & 01 \\
\hline Superficial wound infection & 02 \\
\hline Deep wound infection & 02 \\
\hline Nail migration, olecranon bursitis & 01 \\
\hline Implant failure & 01 \\
\hline Delayed-Union & 02 \\
\hline Non-Union & 01 \\
\hline Total & 10 \\
\hline
\end{tabular}

\section{Discussion}

Here we discuss all the observations found in our series of 25 patients and compare them with previous studies done in the past. The following observations noted:

1. Trauma-Surgery Interval: Dodge and Candy (1972) ${ }^{[14]}$ performed within 7 to 14 days of trauma. Anderson (1975) ${ }^{[4]}$ performed surgeries within 10 days of trauma. Rai et al. (1981) ${ }^{[22]}$ performed surgeries within 3 to 7 days of trauma In the present series, the average interval between the onset of trauma and the time of surgery is about 1 to 5 days in about 10 cases (40\%)

2. Treatment Modality: Knight and Purvis (1949) [18] performed nailing in 11 patients and plating in 20 patients 
Smith and Sage (1959) ${ }^{\text {[23] }}$ performed nailing in 451 patients and plating in 33 patients Jinkins and Associates (1960) ${ }^{[17]}$ performed nailing in 22 patients and plating in 145 patients In the present series, nailing is performed in 11 patients (44\%), plating in 10 patients (40\%) and hybrid fixation in 4 patients (16\%).

3. Post-operative immobilisation: Dodge and Candy (1972) [14] had average period of post-operative immobilisation for 7 to 10 days. Anderson (1975) ${ }^{[5]}$ had average period of post-operative immobilisation for 6 to 8 weeks. Rai et al. (1981) ${ }^{[22]}$ had average period of postoperative immobilisation for 3 to 4 weeks. In the present series, average period of post-operative immobilisation about 6 weeks.

4. Union time: Knight and Purvis (1949) ${ }^{[18]}$ in his series of 59 patients had union time of 8.6 weeks and union percentage was $80 \%$. Stage (1959) ${ }^{[23]}$ in his series of 46 patients had union time of 11.2 weeks and union percentage was $88.9 \%$. Marek (1961) ${ }^{[21]}$ in his series of 32 patients had union time of 8.2 weeks and union percentage was $100 \%$. Anderson (1975) ${ }^{[4]}$ in his series of 244 patients had union time of 7.4 weeks and union percentage was $97.1 \%$. Rai et al. (1981) ${ }^{[22]}$ in his series of 37 patients had union time of 10 weeks and union percentage was $100 \%$. In the present series, the average union time was 6.3 weeks.

5. Complications: Dodge and Candy (1972) ${ }^{[14]}$ noted superficial wound infection in $25 \%$, deep wound infection in $2.9 \%$, delayed union in $1.6 \%$, non-union in $3.6 \%$, refracture in $3.4 \%$, metal reaction in $0 \%$, neuropraxia in $2 \%$, synostosis in $1.2 \%$ of cases. Anderson $(1975)^{[4]}$ noted superficial wound infection in $5.4 \%$, deep wound infection in $5.4 \%$, delayed union in $5.4 \%$, nonunion in $0 \%$, refracture in $0 \%$, metal reaction in $2.7 \%$, neuropraxia in $0 \%$, synostosis in $0 \%$ of cases. Rai et al. (1981) ${ }^{[22]}$ noted superficial wound infection in $18.6 \%$, deep wound infection in $7.1 \%$,delayed union in $7.1 \%$, non-union in $0 \%$, refracture in $3.5 \%$, metal reaction in $7.1 \%$, neuropraxia in $18.6 \%$, synostosis in $0 \%$ of cases. In the present series, we noted superficial wound infection in $8 \%$, deep wound infection in $4 \%$, delayed union in $8 \%$, non-union in $4 \%$, refracture in $4 \%$, metal reaction in $0 \%$, neuropraxia in $4 \%$, nail migration in $4 \%$ of cases.

6. Results: Charnley (1952) ${ }^{[12]}$ excellent results in $69.8 \%$, good results in $29.3 \%$, and poor results in $0.8 \%$ of patients. Dodge and Candy (1972) ${ }^{[14]}$ excellent results in $82.4 \%$, good results in $7.1 \%$, and poor results in $10.5 \%$ of patients. Anderson (1975) ${ }^{[4]}$ excellent results in $54.5 \%$, good results in $27.6 \%$, and poor results in $15 \%$ of patients. Mitchels (1976) ${ }^{[20]}$ excellent results in $84 \%$, good results in $12 \%$, and poor results in $4 \%$ of patients. In the present series, excellent results in $56 \%$, good results in $32 \%$, and poor results in $12 \%$ of patients.

\section{Conclusion}

1. The functional results of nailing, plating and hybrid fixation are comparable.

2. 2. The so called fracture diseased i.e. joint stiffness, muscle wasting and chronic edema is rare after early postoperative mobilisation which is possible in the plated group

3. Primary bone union will occur in the presence of full use of the extremity as long as rigid fixation is maintained which is possible by plating.
4. Function of the forearm is dependent upon both stability and mobility which is possible by plating.

5. The individual can resume his pre-fracture duties much earlier than other methods. This decreases the hospital stay, morbity and work loss.

6. A six hole plate of at least 3.5 inches length should be used for satisfactory results. The plate should be applied on the tension surface of the bone.

7. Restoration of the normal radial bow and ulnar length will prevent subluxation of either the proximal or the distal radio ulnar joint and will re-establish length to the muscles controlling the hand.

8. Restoration of rotational alignment is essential for normal pronation-supination function of the forearm.

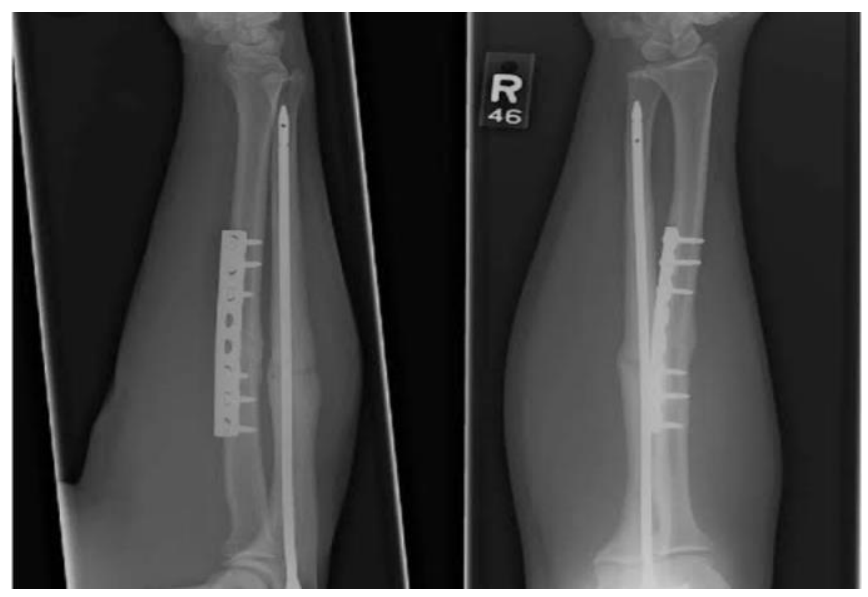

Case 1: Hybrid fixation with Radius Plating and Ulna Nailing.

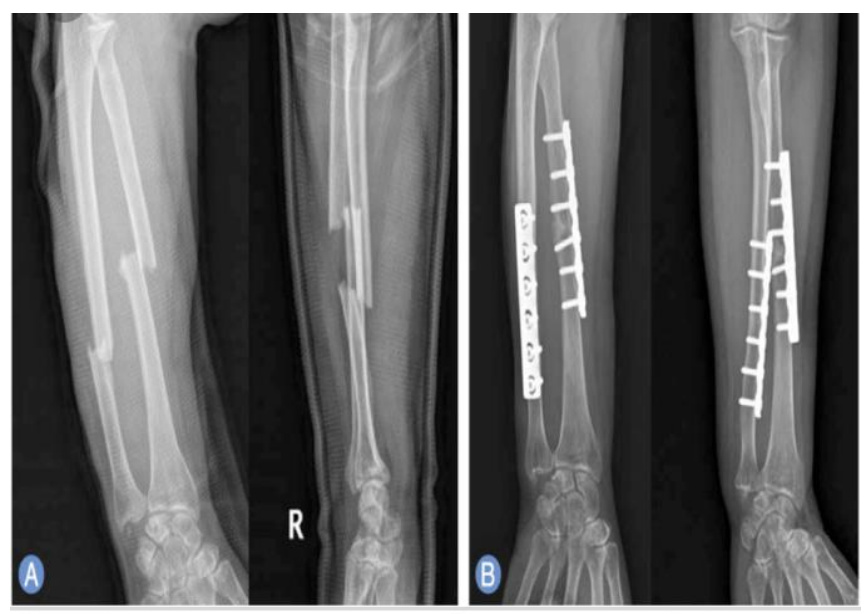

Case 2: Radius Ulna fixation with Plating

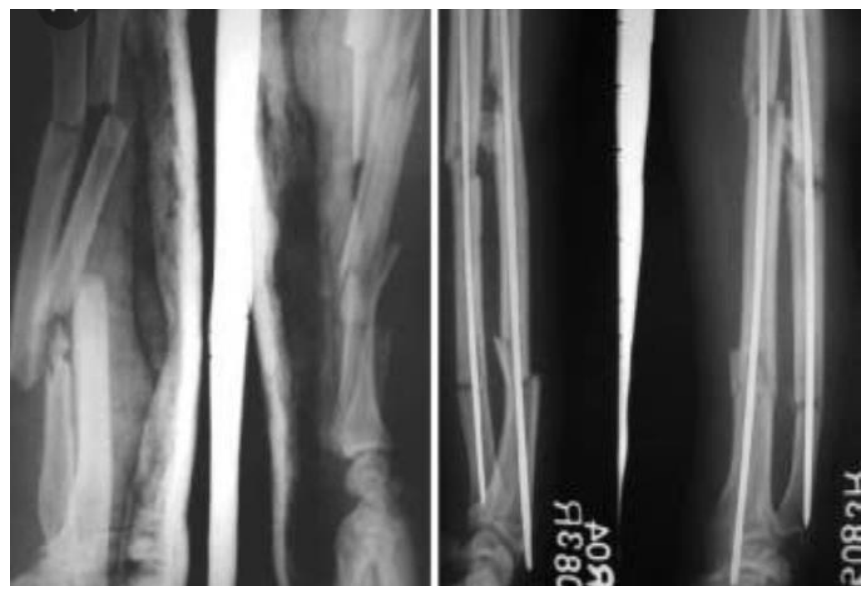

Case 3: Radius Ulna fixation with Nailing 


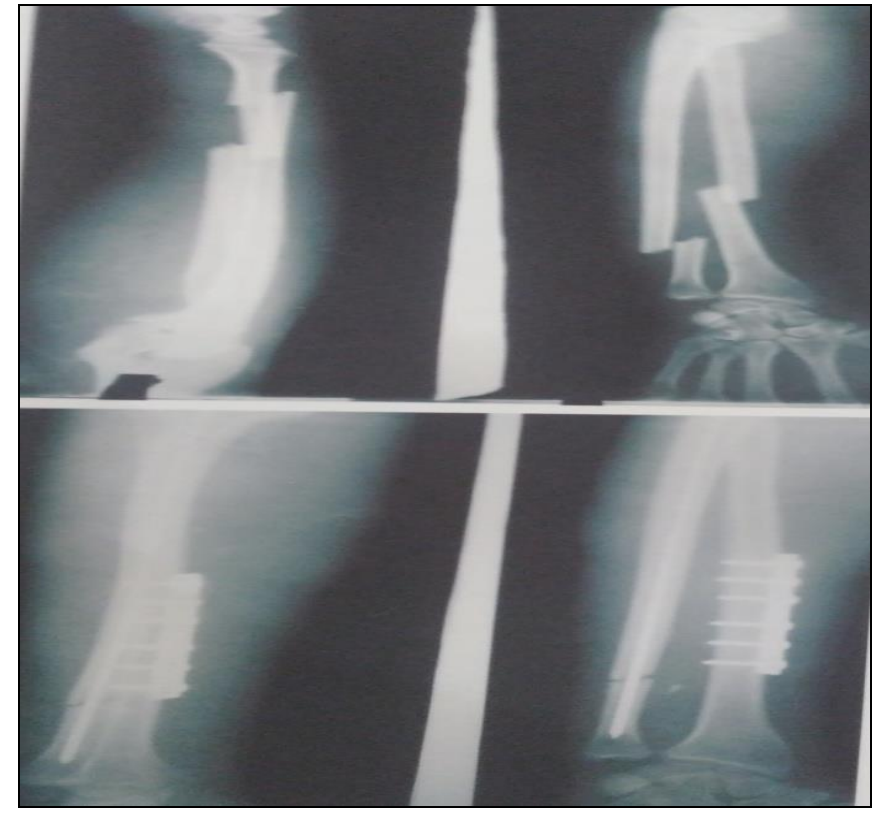

Case 4: Radius Ulna Hybrid fixation with Ulna Nonunion.

\section{References}

1. Allgower M, Muller P, Perren SM et al: The dynamic compression plate (DCP). New York, Springer Verly 2.5, 1978

2. Altesonian, Woo SLW. Rutherford: The effects of rigidity of internal fixation on long bones remodelling. A a biochemical and quantitative histological study. Acta. Ortho. Scand. 1976; 47:241

3. Anderson LD. Compression plate fixation and the effects of different types of internal fixation of fracture healing. Journal of Bone and Joint Surgery. 1985; 17A:191-208.

4. Anderson LD, Sisk TD, Tooms RE. Compression plate fixation in acute diaphyseal fracture radius/ ulna. Journal of Bone and Joint Surgery. 1975; 57A:287.

5. Arbuthronot LW. The operative treatment of fractures. Second Edition, London Medical Publication Co., 1914.

6. Bagby KW. Compression wire plating- A historical consideration. Journal of Bone and Joint Surgery. 1977; 59A:625.

7. Bagby KW. Fracture treated with Bagby compression bone plate.- 18 years experience. Journal of Bone and Joint Surgery. 1975; 57A:1031.

8. Baker GI, Burkhalter WE et al. Treatment of forearm shaft fractures by long slotted plates. Journal of Bone and Joint Surgery. 1969; 51A:1035,

9. Bassett CAL, Rued TP. Transformation of fibrous tissue to bone. Natur. 1966; 209:986-87

10. Batten RL. The place of compression technique in the management of fractures of long bones in an industrial city. Journal of Bone and Joint Surgery. 1964; 51B:177.

11. Caden K. Internal fixation for fracture forearm bones. Journal of Bone and Joint Surgery. 43A:1115.

12. Charnley John, Baker SL. Compression arthrodesis of the knee-A clinical and histological study. Journal of Bone and Joint Surgery. 1952, 34B.

13. De Buren N. Causes of treatment of non-union of fracture radius and ulna. Journal of Bone and Joint Surgery, 44B:614-62.

14. Evans EM. Fractures of radius and ulna. Journal of Bone and Joint Surgery, 33B, 548-501.

15. Frederick M, Marek MD. Axial fixation of forearm fractures. New-York N.Y., 43A, 1099.
16. Henry. Complete exposure of radius. British Journal of Surgery, 13, 506

17. Jinkins WJ. Fractures of forearm bones in adults. Southern Medical journal. 53, 669.

18. Lane MA. Publication Company, 1914.

19. Muller ME. Internal fixation for fresh fractures and for non-union. Proceeding, Royal Society of Medicine.

20. Murray CR. Detailed operative technique for open reduction and internal fixation of fractures of bones. Journal of Bone and Joint Surgery, 26, 307.

21. Nicoll CA. Fixation compression and osteogenesis. Journal of Bone and Joint Surgery, 458, 800,63.

22. Talwalkar AJ. Treatment of fractures of forearm bones with square nails. Journal of Bone and Joint Surgery, 1963, 47B.

23. Thompson. Anatomical methods of approach in operation on the long bones of the extremities.

24. Watson Jones. Fractures and joint injuries. Churchill Livingstone, 1982, 684.

25. Uhtohff HK, Dubne FL. The advantages of less rigid fixation. JBJS. 1980; 62B:524. 